\title{
Epidemiological Aspects of Cutaneous Leishmaniasis in Iran
}

\author{
Salman Khazaei ${ }^{1}$; Abdollah Mohammadian Hafshejani ${ }^{2}$; Mohammad Saatchi ${ }^{3}$; Hamid \\ Salehiniya ${ }^{3,4,} ;$ Shahrzad Nematollahi ${ }^{3}$ \\ ${ }^{1}$ Department of Epidemiology and Biostatistics, School of Public Health, Hamadan University of Medical Sciences, Hamadan, IR Iran \\ ${ }_{3}^{2}$ Department of Epidemiology and Biostatistics, School of Public Health, Isfahan University of Medical Sciences, Isfahan, IR Iran \\ ${ }^{3}$ Department of Epidemiology and Biostatistics, School of Public Health, Tehran University of Medical Sciences, Tehran, IR Iran \\ ${ }^{4}$ Minimally Invasive Surgery Research Center, Iran University of Medical Sciences, Tehran, IR Iran \\ ${ }^{*}$ Corresponding author: Hamid Salehiniya, Minimally Invasive Surgery Research Center, Iran University of Medical Sciences, Tehran, IR Iran. Tel:+98-9357750428, Fax: +98-8134952400, \\ E-mail:alesaleh70@yahoo.com
}

Received: March 8, 2015; Revised: May 18, 2015; Accepted: May 24, 2015

\begin{abstract}
Background: The prevalence of Cutaneous Leishmaniasis (CL) has been reported as 1.8\% to 37.9\% in different provinces of Iran. However, enough knowledge about epidemiological aspects of CL disease is needed to launch a proper program to plan control and preventive strategies about the disease.

Objectives: The present study aimed to determine the epidemiological aspect of CL in Iran during the first 6 months of 2014.

Patients and Methods: In this cross-sectional study, all cases of CL reported to centers for disease control and prevention (CDC) by state health departments from March 2014 to September 2014 were included. Descriptive statistics including frequency tables, measures of central value, and measures of dispersion to describe the study variables were used to analyze data.Area maps were created using ArcView GIS v.3.3.

Results: Most of the CL cases were observed in eastern, central, and southern provinces. Two thousand thirty-one cases (55.13\%) were male and 2,306 (62.6\%) were living in urban areas. The mean age of the patients was $27 \pm 18$ years old. More than $31 \%$ of them were under 14 years of age. Also, 3570 individuals (96.91\%) were new cases. more wounds were seen so that $62.75 \%$ of the wounds were on the hands, $24.8 \%$ in the head and neck, and $2.7 \%$ in the body.

Conclusions: According to the epidemiological features of CL in Iran, Providing a uniform mechanism for control and prevention of this disease is not possible. Thus, initial actions such as staff training, screening in endemic areas, and treatment of patients with urban leishmaniasis as a reservoir for the disease can be useful, according to the geographical position and carrier.
\end{abstract}

Keywords: Cutaneous Leishmaniasis; Epidemiology; Iran

\section{Background}

Leishmaniasis is a vector-borne disease, caused by obligate intracellular protozoa of the genus Leishmania and transmitted by phlebotomine sandflies Cutaneous Leishmaniasis (CL) exists in two epidemiological forms: zoonotic CL, due to L. major which provided in rural areas where the gerbil is the main reservoir host, and anthroponotic CL is caused by L. tropica in large and medium size cities, where humans are the main reservoir host (1). Cutaneous leishmaniasis is endemic in 88 countries worldwide, with more than 350 million people at risk and incidence of 1.5 - 2 million new cases annually (2). Approximately, 90\% of CL cases occur in Afghanistan, Algeria, Iran, Iraq, Saudi Arabia, Syria, Brazil, and Peru (3).

It is estimated that CL is the ninth cause of disease burden among individual infectious diseases (4). Cutaneous leishmaniasis is an important health problem in many countries of the southern and eastern Mediterranean, with diversity of clinical manifestations from simple and single lesions to extensive lesions. Despite the spontaneous healing of these lesions, the facial scars can be a social stigma, especially for women (5).

In our country, CL occurs in several old urban foci, where cases are most often observed in young children, as the older population is immune due to previous contacts with the parasite. In the district of Bam city (one of the closest towns to the south of Iran), there has been an eightfold increase in the number of cases reported over the last five years after the 2003 earthquake (6). Studies showed that the increase in CL incidence in regions is attributed to new settlements, urbanization, agricultural development, migration, improvement of reporting sys-

Copyright (C) 2015, Infectious Diseases and Tropical Medicine Research Center. This is an open-access article distributed under the terms of the Creative Commons Attribution-NonCommercial 4.0 International License (http://creativecommons.org/licenses/by-nc/4.0/) which permits copy and redistribute the material just in noncommercial usages, provided the original work is properly cited. 
tems and ecological changes (7-9).

The prevalence of infection has been reported as 1.8\% to $37.9 \%$ in different provinces of Iran $(10,11)$. However, enough knowledge about epidemiological aspects of the CL disease is needed to launch a proper program to plan control and preventive strategies about the disease.

\section{Objectives}

The present study was performed to determine the epidemiological aspect of CL in Iran during 6 months of 2014.

\section{Patients and Methods}

In this cross-sectional study, all cases of CL reported to CDC by state health departments from March 2014 to September 2014 were enrolled.

Cutaneous leishmaniasis is included in the list of mandatory notifiable diseases in Iran. In other words, private clinics, laboratories, and public centers are committed to report all of diagnosed CL cases to the department of preventive diseases. Islamic Republic of Iran is located in west of Asia with a population of about 78 million people and an area of 1,648,195 $\mathrm{km}^{2}$.

A confirmed CL case is an individual with clinical manifestations, compatible with CL (appearance of skin lesions, nodular or ulcerative, usually on exposed areas of the body, which can be followed in some cases by the appearance of mucosal lesions), and laboratory confirmation via detection of the pathogen on clinical samples (if only mucosal lesions exist, laboratory confirmation will be performed via serology).

The checklist used included demographic information, such as age, gender, occupation, a history of travel in the past year, and the travel location), clinical information (a history of previous scar, the location and size of the wound, the number of wound, the shape of wound, and the type of treatment regimen).

To analyze data, description measures such as frequency tables, measures of statistical central and dispersion values were used. All the analyses were done using STATA software version 11 (Stata Corp, College Station, Texas, USA). Additionally, area maps were created using ArcView GIS v. 3.3.

\section{Results}

Overall, 3684 patients with CL were reported to CDC from March 2014 to September 2014 in Iran. The geographic distribution of cases according to the province is shown in Figure 1. Most of the cases were observed in eastern, central, and southern provinces in the way that the most frequent cases were in Khorasan-e-Razavi (1134 cases) Fars (630 cases), and Kerman (465 cases), while north and northwest areas had reported fewer cases.

Demographic characteristics of the study population are shown in Table 1. According to nationality, the pa- tients classified into Iranian patients (3431, 93.14\%), Afghanis (246, 6.68\%), Pakistanis (4, 0.11\%), and were Iraqi (3, 0.08\%). Overall, 2031 cases (55.13\%) were male and 2,306 $(62.6 \%)$ were living in urban areas. The mean age of patients was $27 \pm 18$.

In addition, more than $31 \%$ of the participants were under 14 years of age while $10.53 \%$ of them were found to be over 55 years. In this study, 2235 subjects ( $60.67 \%$ ) were related to health centers, $2.3 \%$ and $21.2 \%$ for hospitals and the private sector, respectively. Only 963 (26.14) of the patients reported a history of travel in the past year and $1.1 \%$ of them had a history of previous scar. Occupational status of the patients is shown in Figure 2. Housewives had the highest incidence (25.05\%), following by students and children (incidence rate: $19.16 \%$ $12.76 \%$, respectively).

Clinical characteristics of the study population are shown in Table 2. Among study subjects, 3570 individuals (96.91\%) were new cases. Treatment failure was reported in less than $1 \%$ of the patients. More wounds were seen in open and uncovered organs of the body such that $62.75 \%$ of wounds were seen on the hands, $24.8 \%$ in the head and neck, and $2.7 \%$ in other parts of the body. In over half of the cases (53.18\%), wound size was one or less than one centimeter but about $6 \%$ of the wound were more than 4 centimeters. The shape of ulcer wound without purulent discharge was seen in 2472 patients (67.1\%) and there were about $32 \%$ of cases with ulcers and purulent discharge. Only one wound was observed in $53.23 \%$ of the cases while there were about $16.4 \%$ with more than three ulcers in the organs. Nearly, all of the cases (97\%) reported any underlying disease.

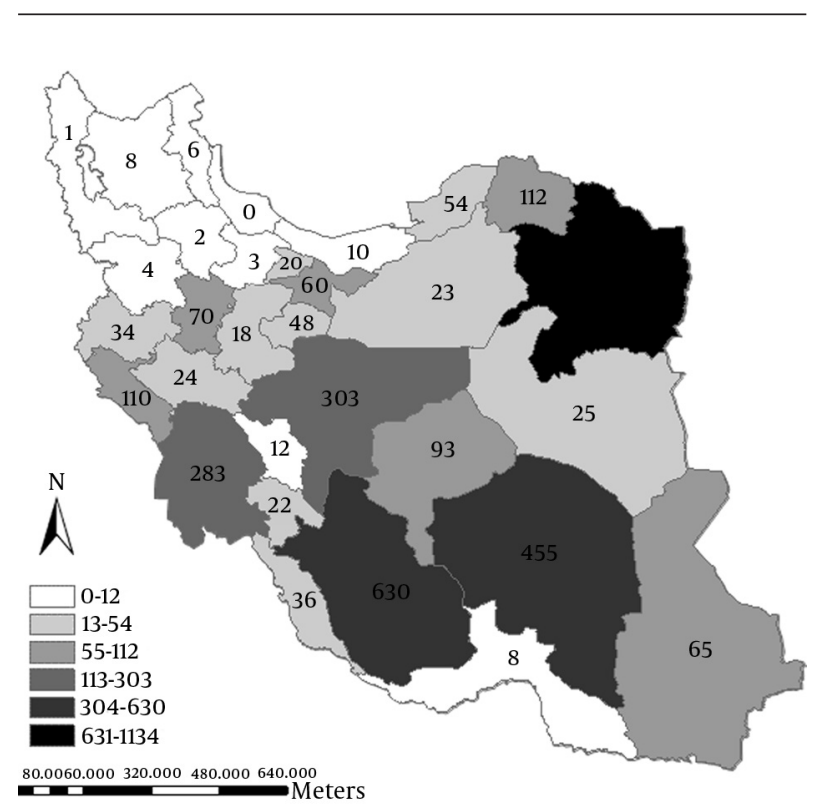

Figure 1. Distribution of Cutaneous Leishmaniasis Cases, by the Province 
Table 1. Distribution of the Demographic Characteristics in Cutaneous Leishmaniasis Patients ${ }^{\mathrm{a}}$

\begin{tabular}{|c|c|}
\hline Variables & Number \\
\hline \multicolumn{2}{|l|}{ Gender } \\
\hline Male & $2031(55.13)$ \\
\hline Female & $1653(44.87)$ \\
\hline \multicolumn{2}{|l|}{ Age group, y } \\
\hline $0-14$ & $1146(31.11)$ \\
\hline $15-24$ & $673(18.27)$ \\
\hline $25-44$ & $1132(30.73)$ \\
\hline $45-54$ & $345(9.36)$ \\
\hline More than 55 & $388(10.53)$ \\
\hline \multicolumn{2}{|l|}{ Location } \\
\hline Urban & $2306(62.6)$ \\
\hline Rural & $1352(36.7)$ \\
\hline Mobile & $26(0.71)$ \\
\hline \multicolumn{2}{|l|}{ Scar history } \\
\hline No & 3644 (98.9) \\
\hline Yes & $40(1.1)$ \\
\hline \multicolumn{2}{|l|}{ Nationality } \\
\hline Iranian & $3431(93.14)$ \\
\hline Afghan & $246(6.68)$ \\
\hline Pakistan & $4(0.11)$ \\
\hline Iraq & $3(0.08)$ \\
\hline \multicolumn{2}{|l|}{ Travel history b } \\
\hline Yes & $963(26.14)$ \\
\hline No & $2721(73.86)$ \\
\hline \multicolumn{2}{|l|}{ Referral unit } \\
\hline Health centers & 2235 (60.67) \\
\hline Health houses & $243(6.6)$ \\
\hline Private centers & $781(21.2)$ \\
\hline Hospitals & $86(2.3)$ \\
\hline By self & $18(0.5)$ \\
\hline Others & $321(8.7)$ \\
\hline
\end{tabular}

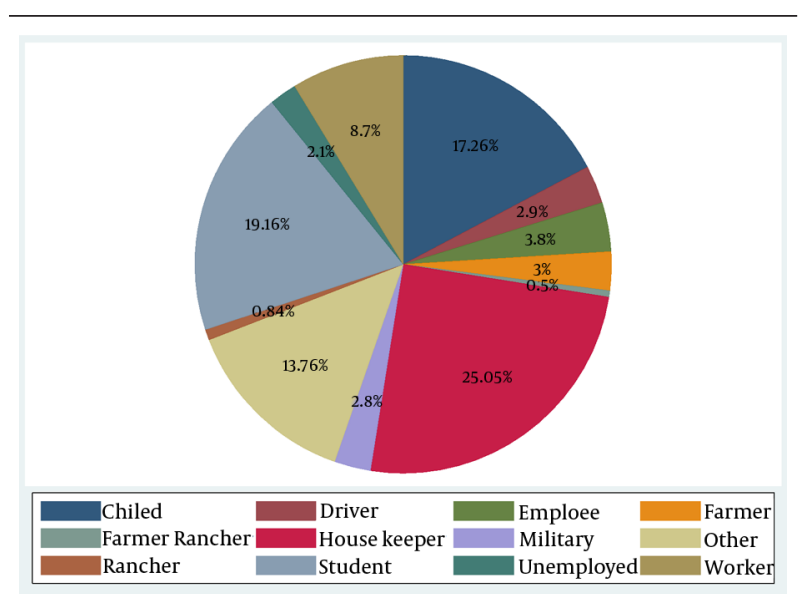

Figure 2. Occupational Status of the Patients With Cutaneous Leishmaniasis
Table 2. Distribution of the Clinical Characteristics in Cutaneous Leishmaniasis Patients ${ }^{\text {a }}$

\begin{tabular}{|c|c|}
\hline Variables & Frequency \\
\hline \multicolumn{2}{|l|}{ Disease type } \\
\hline New case & $3570(96.91)$ \\
\hline Failure & $32(0.87)$ \\
\hline Recurrence & $57(1.54)$ \\
\hline Other & $25(0.67)$ \\
\hline \multicolumn{2}{|l|}{ Lesion Location } \\
\hline Hand & $2312(62.75)$ \\
\hline Face and neck & $915(24.8)$ \\
\hline Body & $98(2.7)$ \\
\hline Foot & $837(22.7)$ \\
\hline \multicolumn{2}{|l|}{ Lesion size, $\mathrm{cm}$} \\
\hline 1 & $1959(53.18)$ \\
\hline 2 & $923(25.05)$ \\
\hline 3 & $427(11.59)$ \\
\hline 4 & $152(4.13)$ \\
\hline More than 4 & $223(6.05)$ \\
\hline \multicolumn{2}{|l|}{ Lesion shape } \\
\hline Ulcer and secretions & $1177(31.95)$ \\
\hline Ulcer & $2472(67.1)$ \\
\hline Lupoid & $26(0.71)$ \\
\hline Osporotrikoid & $9(0.24)$ \\
\hline \multicolumn{2}{|l|}{ Lesion number } \\
\hline 1 & $1961(53.23)$ \\
\hline 2 & $769(20.87)$ \\
\hline 3 & $350(9.5)$ \\
\hline More than 3 & $604(16.4)$ \\
\hline \multicolumn{2}{|l|}{ Underlying disease } \\
\hline No & 3584 (97.29) \\
\hline Diabetes & $33(0.9)$ \\
\hline Hypertension & $54(1.4)$ \\
\hline Liver disease & $5(0.13)$ \\
\hline Other & $15(0.41)$ \\
\hline
\end{tabular}

\section{Discussion}

Currently, zoonotic diseases (Zoonosis) are one of the major public health challenges, and due to expanding urbanization, migration types, the speed of deforestation, along with other environmental actions, are considered important health problems (12-15). The CL is one of the major health problems in the Middle East, including Iran and the Mediterranean littoral (16). According to a report submitted to the world health organization in 2008, Iran had the highest prevalence of the disease in the region, with 26,869 new cases which more than 67 percent of them were rural residents (17). Notwithstanding, in the 6 -month study period, more than $62 \%$ of cases were urban residents indicating a change in the epidemiological pattern in the country. It is noteworthy that in the foci of rural zoonotic CL, seasonal distribution of the disease usually begins from September and reaches its peak in 
December. Therefore, considering duration of the study, it is expected that rural cases are more than what have been found throughout the year. High frequency of $\mathrm{CL}$ in Iran can be investigated from two aspects. First, the high frequency could be due to the border with three countries: Iraq, Afghanistan, and Pakistan. As also shown in this study, nearly $7 \%$ of those detected in the country in the period of 6 months were immigrants from the aforementioned countries. Because of illegal immigration to the country by many Afghan nationals, living in high risk areas, and lack of adequate access to health services, underestimated rates are likely expected. Second, there is greater sensitivity of the surveillance system in detection and treatment of the disease in the country compared with other countries in the region. However, many experts believe that there is undercount or underestimation of the disease due to lack of awareness of the symptoms of the disease (16). Our findings, similar to other studies, showed that tropical regions in Iran like Khorasan, Fars, and Kerman provinces had the highest incidence of the disease consistently $(18,19)$. Other studies expressed that the effect of temperature and climatic conditions is known as a risk factor for the life cycle of the carrier, the frequency in animal reservoirs, and the transmission pattern of the predominant type pathogen (2022). It is somewhat difficult to compare the distribution of age groups according to different designs and classification in various studies (23). Our study indicated that age group of o to 14 years had the highest rates, which is similar to studies performed in Turkey and Greece (20, 24) while in a study conducted in Brazil the lowest prevalence was seen in this age group (25). Given that infection with Leishmania provides immunity against reinfectin with the same parasite, most children will be infected in endemic areas. It is important to pay more attention to undercount of $\mathrm{CL}$ in this age group because of impetigo and folliculitis (26). The age pattern of CL indicates that the disease is commonly seen in children less than ten years; and in areas with lower prevalence, involves adolescences and young people, in addition to children. Our results showed that older age groups also were infected. This may be due to infection in areas where the disease recently occurred. Clinical symptoms of Leishmania parasite, especially major Leishmania, vary in different regions of the world, depending on the type of parasite as nodular, ulcerative, satellite lesions, lymphadenitis, and sporotrichoid $(27,28)$ In this study, consistent with findings obtained from endemic countries, $67 \%$ of the subjects had ulcer $(25,29)$. It has been documented that any painless lesions in endemic regions last more than two weeks should be considered suspicious for CL (16). The location of wound in various regions is also a function of type of mosquito's activity, culture of wearing clothing, and exposure to carrier. In the present study, approximately $87 \%$ of the wounds exist on the hands, face, and neck because of sleeping in the outdoor, without the use of linen and lace, and lack of proper body cover in summer, consider- ing the high prevalence of the disease in tropical regions, while in Brazil more than $34 \%$ of wounds occurred in the legs, given the type of wearing clothing among Brazilians (25). Other studies have also shown a higher frequency of the disease in men $(23,30)$. In our study, $55 \%$ of the cases were men. This may be due to higher exposure to mosquito's bites and business trips to endemic areas. In a 10-year study in England, 71\% of patients admitted to hospital had a history of travel to endemic regions, especially the Mediterranean countries (31). A study in Afghanistan on Dutch soldiers indicated the prevalence of $18.3 \%$ among them because they are susceptible at the time of migration (29). Further studies are needed to determine the role of sex and gender susceptibility. Since $46.7 \%$ of patients had two or more ulcers, we can conclude that some types of Phlebotomus bite more than once a host based on physiological characteristics and feeding habits, and in each bite Leishmania parasites are injected into the blood. It is necessary to identify different types of carriers and their feeding habits in endemic areas to prevent further ulcers (26).

Finally, the main limitation of this study is the short period of this study. Hence, international comparisons are somehow controversial. It is suggested that trend of the disease is evaluated in further studies with a longer period of time. It is also advisable to conduct more analytical studies to determine the role of socioeconomic factors such as poverty, development, human behavior, protein-energy malnutrition, population dynamics, entering nonimmune individuals into inside.

Most patients in this study were from eastern and southern regions of the country with warm weather and dry climate. The greater involvement of patients in the age group 0 to 14 years and prevalence of $25 \%$ in housewives revealed that the vector exists indoor and outdoor places. Therefore, protection and prevention actions should be more aggressively pursued near homes, especially in endemic areas. Open parts of the body, such as the head and face, had more lesion involvement. As a result, more training is required especially in tropical regions and the use of topical ointment to protect open organs. According to the epidemiological features of CL in Iran, providing a uniform mechanism for control and prevention of this disease is not possible.

\section{Acknowledgements}

We would like to thank all the public health experts in the country.

\section{References}

1. Centers for Disease Control and Prevention.. Parasites - Leish maniasis. 2013. Available from: http://www.cdc.gov/parasites/ leishmaniasis/biology.html.

2. World Health Organization.. Urbanization: an increasing risk factor for leishmaniasis. Wkly Epidemiol Rec. 2002;77(44):365-70.

3. Desjeux P. Leishmaniasis: current situation and new perspectives. Comp Immunol Microbiol Infect Dis. 2004;27(5):305-18. 
4. Hotez PJ, Molyneux DH, Fenwick A, Ottesen E, Ehrlich Sachs S, Sachs JD. Incorporating a rapid-impact package for neglected tropical diseases with programs for HIV/AIDS, tuberculosis, and malaria. PLoS Med. 2006;3(5):e102.

5. Salah AB, Kamarianakis Y, Chlif S, Alaya NB, Prastacos P. Zoonotic cutaneous leishmaniasis in central Tunisia: spatio temporal dynamics. Int J Epidemiol. 2007;36(5):991-1000.

6. World Health Organization.. Cutaneous leishmaniasis in the Islamic Republic of Iran.: WHO;. Available from: http://www.emro.who. int/neglected-tropical-diseases/countries/cl-iran.html.

7. Desjeux P. The increase in risk factors for leishmaniasis worldwide. Trans R Soc Trop Med Hyg. 2001;95(3):239-43.

8. Sharifi I, Nakhaei N, Aflatoonian M, Parizi MH, Fekri A, Safizadeh $\mathrm{H}$, et al. Cutaneous leishmaniasis in bam: a comparative evaluation of pre- and post-earthquake years (1999-2008). Iran J Public Health. 2011;40(2):49-56.

9. Croft SL, Sundar S, Fairlamb AH. Drug resistance in leishmaniasis. Clin Microbiol Rev. 2006;19(1):111-26.

10. Yaghoobi-Ershadi MR, Hanafi-Bojd AA, Javadian E, Jafari R, Zahraei-Ramazani AR, Mohebali M. A new focus of cutaneous leishmaniasis caused by Leishmania tropica. Saudi Med J. 2002;23(3):291-4

11. Talari SA, Shajari G, Talaei R. Clinical finding of cutaneous leishmaniasis as a new focus of Iran. Internet J Infec Dis. 2006;5(2):1-5.

12. Mosleh IM, Geith E, Natsheh L, Abdul-Dayem M, Abotteen N. Cutaneous leishmaniasis in the Jordanian side of the Jordan Valley: severe under-reporting and consequences on public health management. Trop Med Int Health. 2008;13(6):855-60.

13. Dhiman RC. Emerging vector-borne zoonoses: eco-epidemiology and public health implications in India. Front Public Health. 2014;2:168.

14. Jacobson RL, Eisenberger CL, Svobodova M, Baneth G, Sztern J, Carvalho J, et al. Outbreak of cutaneous leishmaniasis in northern Israel. J Infect Dis. 2003;188(7):1065-73.

15. Blum J, Desjeux P, Schwartz E, Beck B, Hatz C. Treatment of cutaneous leishmaniasis among travellers. J Antimicrob Chemother. 2004;53(2):158-66.

16. Yavari P. Epidemiology Textbook Prevalent Disease in Iran.Tehran: Gap nashr; 2013.

17. Postigo JA. Leishmaniasis in the World Health Organization Eastern Mediterranean Region. Int J Antimicrob Agents. 2010;36 Suppl 1:S62-5.

18. Javadian E, Nadim A, Tahvildari A. Epidemiology of cutaneous leishmaniasis in Korassan Iran. Bull Soc Path Exot. 1967;69:140-3.

19. Nadim A, Seydi-Rashti MA. A brief review of the epidemiology of various types of leishmaniasis in Iran. Acta Med Iran J Med Sci.
1971;8:99-106.

20. Gkolfinopoulou K, Bitsolas N, Patrinos S, Veneti L, Marka A, Dougas $\mathrm{G}$, et al. Epidemiology of human leishmaniasis in Greece, 1981-2011. Euro Surveill. 2013;18(29):20532.

21. McMichael AJ, Lindgren E. Climate change: present and future risks to health, and necessary responses. J Intern Med. 2011;270(5):401-13.

22. Cross ER, Newcomb WW, Tucker CJ. Use of weather data and remote sensing to predict the geographic and seasonal distribution of Phlebotomus papatasi in southwest Asia. Am J Trop Med Hyg. 1996;54(5):530-6.

23. Gandacu D, Glazer Y, Anis E, Karakis I, Warshavsky B, Slater P, et al. Resurgence of cutaneous leishmaniasis in Israel, 2001-2012. Emerg Infect Dis. 2014;20(10):1605-11.

24. Ok UZ, Balcioglu IC, Taylan Ozkan A, Ozensoy S, Ozbel Y. Leishmaniasis in Turkey. Acta Trop. 2002;84(1):43-8.

25. Murback ND, Hans Filho G, Nascimento RA, Nakazato KR, Dorval ME. American cutaneous leishmaniasis: clinical, epidemiological and laboratory studies conducted at a university teaching hospital in Campo Grande, Mato Grosso do Sul, Brazil. An Bras Dermatol. 2011;86(1):55-63.

26. Talari SA, Talaei R, Shajari G, Vakili Z, Taghaviardakani A. Childhood cutaneous leishmaniasis: report of 117 cases from Iran. Korean J Parasitol. 2006;44(4):355-60.

27. Elfari M, Schnur LF, Strelkova MV, Eisenberger CL, Jacobson RL, Greenblatt CL, et al. Genetic and biological diversity among populations of Leishmania major from Central Asia, the Middle East and Africa. Microbes Infect. 2005;7(1):93-103.

28. Gaafar A, Fadl A, el Kadaro AY, el Hassan MM, Kemp M, Ismail AI, et al. Sporotrichoid cutaneous leishmaniasis due to Leishmania major of different zymodemes in the Sudan and Saudi Arabia: a comparative study. Trans R Soc Trop Med Hyg. 1994;88(5):552-4.

29. van Thiel PP, Leenstra T, de Vries HJ, van der Sluis A, van Gool T, Krull AC, et al. Cutaneous leishmaniasis (Leishmania major infection) in Dutch troops deployed in northern Afghanistan: epidemiology, clinical aspects, and treatment. Am J Trop Med Hyg. 2010;83(6):1295-300.

30. Amro A, Gashout A, Al-Dwibe H, Zahangir Alam M, Annajar B, Hamarsheh O, et al. First molecular epidemiological study of cutaneous leishmaniasis in Libya. PLoS Negl Trop Dis. 2012;6(6):e1700.

31. Wall EC, Watson J, Armstrong M, Chiodini PL, Lockwood DN. Epidemiology of imported cutaneous leishmaniasis at the Hospital for Tropical Diseases, London, United Kingdom: use of polymerase chain reaction to identify the species. Am J Trop Med Hyg. 2012;86(1):115-8. 